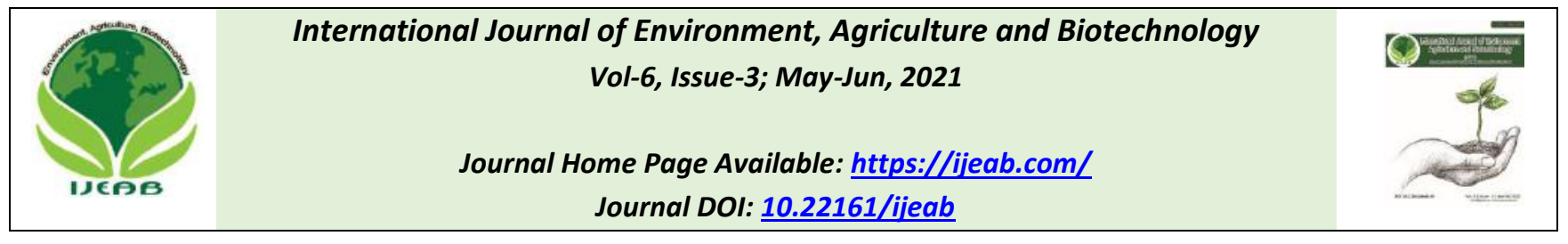

Article

Peer-Reviewed Journal

\title{
Adding Functional Foods to Fermented Snake Melon (Cucumis melo var. flexuosus) to Increase Consumption and Reduce Crop Loss
}

\author{
Lynn Sleiman ${ }^{1}$, Ali Alkhatib ${ }^{1}$, Sami Tlais ${ }^{2}$, Hassan Hajj Hussein ${ }^{2 *}$
}

${ }^{1}$ Department of Nutrition and Food Science, Lebanese International University, Lebanon

${ }^{2}$ Department of Biological and Chemical Sciences, Lebanese International University, Lebanon

*Corresponding author. Email address: hassan.hajjhussein@liu.edu.lb

Received: 11 Apr 2021; Received in revised form: 04 May 2021; Accepted: 28 May 2021; Available online: 13 Jun 2021 (C2021 The Author(s). Published by Infogain Publication. This is an open access article under the CC BY license (https://creativecommons.org/licenses/by/4.0/).

\begin{abstract}
Snake melon (Cucumis melo var. flexuosus) is a member of the melon family. It is a seasonal fruit that is high in water and low in calories, fat, and cholesterol. It is a high-yielding crop that has a short shelflife, which results in the loss of a high percentage of the annual yield. In order to reduce the percentage of lost crop, we proposed several new recipes for making pickled snake melon by adding functional foods to enhance the flavor and nutritional values of the pickled snake melon product while evaluating consumer acceptance using sensory evaluation. The different samples of snake melon pickles were analyzed for their sensory attributes (color, odor, texture, taste, saltiness, sourness, and overall acceptability) using a Likert scale ranging from 1 "least liked" to 5 "most liked". While none of the tested recipes were preferred over the control, four of the new recipes were similar to the control in overall acceptability indicating a clear potential for incorporating functional foods to increase diversification of snake melon pickles and in essence increase the potential for snake melon consumption while reducing crop loss.
\end{abstract}

Keywords-Snake melon, Armenian cucumber, Mekte, Cucumis melo, functional foods.

\section{INTRODUCTION}

The snake or Armenian cucumber (Cucumis melo var. flexuosus), also known as snake melon, is a member of the melon family [1]. It is a type of long, curved, slender fruit which resembles and tastes like cucumber. It is known as Fakous in North Africa and some Arabic countries, Alficoz in Spain, Tortarello, Citrangolo, or Cucummaru in Italy, Hiti in Turkey, Tirozi in Kurdistan, Uri in Japan, and Mekte in Lebanon and Syria [2]. It originated in the Mediterranean basin, North Africa, Middle East, and Anatolia [3]. It is grown in house gardens as well as large scale farms [4].

Snake melon is an ancient crop that flourishes in sunny and warm climates [4]. It is characterized by a variety of external colors, which can be light green, dark green, or a mixture of both [2]. Other differences can be detected by the presence or absence of pubescence on the skin and by the longitudinal ribbing on the fruits, which ranges from very shallow to very deep [2]. It is used in the same applications as cucumber and therefore is considered an alternative to cucumber in many parts of the world [3]. Snake melon seeds contain $15.57 \%$ protein, $16.19 \%$ carbohydrate, and $5.69 \%$ ash. It is a good source of oil since the seed is composed of $22.33 \%$ oil. Snake melon seed oil is characterized by its odor, good color, good appearance, and good physicochemical properties [5].

Snake melon is characterized by a high yield and a short shelf-life [3]. According to the Biotechnology Research Institute of the Iranian Ministry of Agriculture, more than $17 \%$ of the 106 million tons of snake melon produced in Iran became unusable in different stages from production to supply, and $7 \%$ perished in stores due to inappropriate packaging and unsuitable storage methods [1]. 
There is an increase in public interest in functional foods due to their positive impact on health [6]. Functional foods are foods or food ingredients that benefit the health in more than the nutrients it contains [6]. Garlic is characterized by the highest fructan fractions compared to many fruits and vegetables and could be considered as a potential source of prebiotics to be used to functional food products [7]. Garlic contains high amounts of sulfur-containing compounds compared to onions, broccoli, cauliflower and apricots [8]. It was suggested that incorporating garlic into food products such as bakery and meat products rendering them the characteristics of functional foods [9]. Beetroot (Beta vulgaris rubra) could be considered as functional food because of its content of betalains and phytochemicals [10].Jalapeno pepper (Capsicum annuum L) is one of the key foods in the Mexican Diet. Its high concentrations of antioxidants and functional compounds gives it a significant role in human health [11]. Black pepper (Piper nigrum) contains piperine that inhibits lipid peroxidation and it improved the memory impairment and neurodegeneration in hippocampus [12]. Also, its rich phytochemistry includes volatile oil, oleoresins, and alkaloids. Its antioxidant, antimicrobial potential, and gastro-protective modules make it a significant healthy food [13]. Ginger (Zingiber oficinale) is a potential functional food and its addition to food may reduce chronic diseases and mineral deficiency [14]. It is considered as a rich source of raw fibers, phenolic compounds, organic acids, terpenes, lipids, and polysaccharides. Its content of phenolic compounds such as shogaols and gingerols contributes to its health benefits [15].

The objective of this study is to develop new recipes of snake melon pickles in an effort to decrease food wasting by adding functional foods to enhance the flavor and nutritional values of the pickled snake melon product while evaluating consumer acceptance using sensory evaluation with emphasis on odor, color, mouth texture, taste, saltiness, sourness, and overall acceptability. This will help in creating additional ways of consuming an otherwise perishable product while introducing new products on supermarket shelves to accommodate the ever-growing complexities of consumer palates.

\section{METHODS AND MATERIALS}

\section{$2.1 \quad$ Materials}

In September, fresh snake melon fruits of equal maturity were collected from the fields of Bednayel, Lebanon. Any damaged, bruised, or infected fruits were discarded. Pickling salt, white crystalized sugar, vinegar (5\% acetic acid), packaged and sealed spices, and garlic were purchased from the local market.

\subsection{Sample preparation}

Nine recipes for snake melon pickle were standardized (Table 1). Fruits were washed and cut into equally sized pieces to better fit into the pickling jars. Snake melon was added first. Salt and vinegar were mixed with water in a large bowl and used to fill up the glass jars until the fruits were completely covered. Additional flavoring ingredients were added to the jars before they were capped tightly and stored at room temperature.

Table 1:Recipes for snake melon pickle including the name of the flavor and amount added

\begin{tabular}{l|lllll}
\hline & $\begin{array}{l}\text { Snake } \\
\text { melon }\end{array}$ & Salt & Vinegar & Water & $\begin{array}{l}\text { Amount } \\
\text { of } \\
\text { flavoring }\end{array}$ \\
\hline CTR & $200 \mathrm{~g}$ & $25 \mathrm{~g}$ & $33 \mathrm{ml}$ & $350 \mathrm{ml}$ & \\
Black Pepper & $200 \mathrm{~g}$ & $25 \mathrm{~g}$ & $33 \mathrm{ml}$ & $350 \mathrm{ml}$ & $10 \mathrm{~g}$ \\
Ginger & $200 \mathrm{~g}$ & $25 \mathrm{~g}$ & $33 \mathrm{ml}$ & $350 \mathrm{ml}$ & $10 \mathrm{~g}$ \\
Garlic & $200 \mathrm{~g}$ & $25 \mathrm{~g}$ & $33 \mathrm{ml}$ & $350 \mathrm{ml}$ & $10 \mathrm{~g}$ \\
Jalapeno Pepper & $200 \mathrm{~g}$ & $25 \mathrm{~g}$ & $33 \mathrm{ml}$ & $350 \mathrm{ml}$ & $2.5 \mathrm{~g}$ \\
Sugar & $200 \mathrm{~g}$ & $25 \mathrm{~g}$ & $33 \mathrm{ml}$ & $350 \mathrm{ml}$ & $10 \mathrm{~g}$ \\
Citric Acid salt & $200 \mathrm{~g}$ & $25 \mathrm{~g}$ & $33 \mathrm{ml}$ & $350 \mathrm{ml}$ & $2.5 \mathrm{~g}$ \\
Chickpeas & $200 \mathrm{~g}$ & $25 \mathrm{~g}$ & $33 \mathrm{ml}$ & $350 \mathrm{ml}$ & $10 \mathrm{~g}$ \\
Red Beets & $200 \mathrm{~g}$ & $25 \mathrm{~g}$ & $33 \mathrm{ml}$ & $350 \mathrm{ml}$ & $40 \mathrm{~g}$ \\
\hline
\end{tabular}

\subsection{Sensory analysis}

After 20 days of fermentation, the samples were subjected to sensory evaluation. Sensory analysis consisted of describing the organoleptic properties of the samples. Twenty panelists aged 20 to 45 years, who are regular consumers of pickled snake melon, were advised to rate the samples in terms of odor, color, texture in the mouth, taste, saltiness, sourness, and overall acceptability using an interval Likert scale ranging from 1 to 5 (where " 1 " was "least liked" and "5" was "most liked").

Sample preparation, presentation, temperature, and serving container shape were the same for all tested samples. Samples were served in plastic cups identified by a three-digit code. Mineral water was used as palate cleanser (offered to the panelists between samples). Each sample was blindly analyzed by the sample panelist for a total of three replications.

\subsection{Statistical analysis}

Data were expressed as mean \pm SEM values from three independent replicates. One way analysis of variance was conducted using GraphPad Prism 8.3.0 and the differences were analyzed by Dunnett's Multiple comparisons test.

\section{RESULTS AND DISCUSSION}

\subsection{Odor}

For the test of odor, the panelists evaluated all samples and reported their findings on a Likert scale ranging from 1 to 5 (where "1" was "least liked" and "5" was "most liked"). 
The panelists did not favor any of the samples above the control in terms of the odor; however, they expressed a significant decrease in the liking of the odor of "Ginger" $(3.20 \pm 0.17 ; \mathrm{p}<0.01)$ and "Citric Acid" $(3.10 \pm 0.15 ; \mathrm{p}<0.01)$

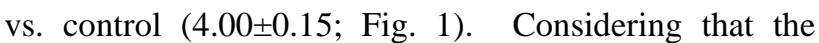
panelists were all Lebanese, it is possible that the panelists did not appreciate the taste of ginger since ginger is not a product that is usually used in Lebanese pickled products. However, for some unknown reason, the panelists seemed to find the smell of citric acid salt somewhat off-putting.

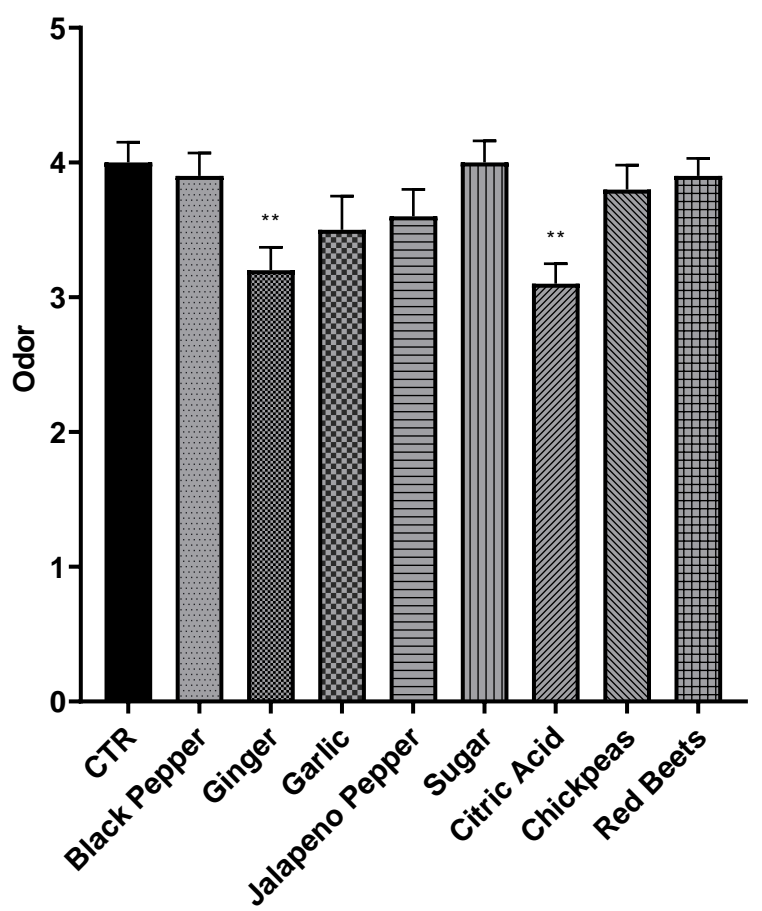

Fig.1: Comparing odor evaluation of all 8 flavors to the control.

\subsection{Color}

For the test of color, the panelists evaluated all samples and reported their findings on a Likert scale ranging from 1 to 5 (where "1" was "least liked" and "5" was "most liked"). The panelists did not favor any of the samples above the control in terms of the color; however, they expressed a significant decrease in the liking of the color of "Citric Acid" (3.30 $\pm 0.18 ; \mathrm{p}<0.001)$ and "Red Beets" $(3.60 \pm 0.32$;

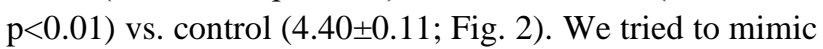
the pinkish color of pickled ginger and pickled turnips. While Lebanese are used to pickled turnips being colored pinkish-red, they are not used to seeing pickled snake melon in that color, which probably explains why the panelists reported a decrease in the liking of the pinkishred colored snake melon pickles compared to the control. In addition, the samples that contained citric acid looked a little more pale and yellow compared to the control.

\subsection{Texture}

For the test of texture or mouthfeel, the panelists evaluated all samples and reported their findings on a Likert scale ranging from 1 to 5 (where " 1 " was "least liked" and " 5 " was "most liked"). The panelists did not report any difference in the texture of any of the eight samples

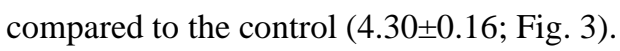

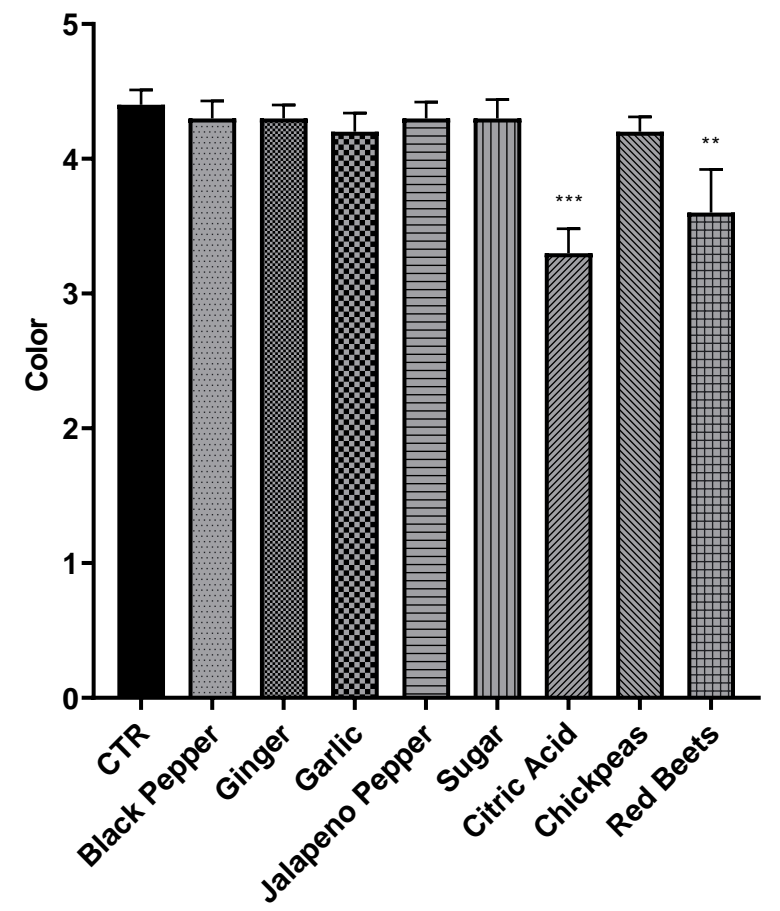

Fig.2: Comparing color evaluation of all 8 flavors to the control.

\subsection{Taste}

For the test of taste, the panelists evaluated all samples and reported their findings on a Likert scale ranging from 1 to 5 (where "1" was "least liked" and " 5 " was "most liked"). The panelists did not favor any of the samples above the control in terms of the taste; however, they expressed a significant decrease in the liking of the taste of "Ginger" $(2.90 \pm 0.18 ; \mathrm{p}<0.001)$ and "Citric Acid" $(3.30 \pm 0.18$; $\mathrm{p}<0.001)$ vs. control ( $4.30 \pm 0.16$; Fig. 4$)$. This is probably due to the same reasons explained in the section about the "Color".

\subsection{Saltiness}

For the test of saltiness, the panelists evaluated all samples and reported their findings on a Likert scale ranging from 1 to 5 (where "1" was "least liked" and "5" was "most liked"). The panelists did not favor any of the samples above the control in terms of the saltiness; however, they expressed a significant decrease in the liking of the saltiness of "Citric Acid" $(3.60 \pm 0.15 ; \mathrm{p}<0.05)$ vs. control (4.30 \pm 0.16 ; Fig. 5). Sourness and saltiness are commonly 
called the electrolytic tastes where in both instances small soluble inorganic cations are the stimulants [6]. In our experiment we used sodium citrate as citric acid salt. Since it contains sodium, this would explain why the panelists perceived the sample to be salty and therefore was less liked.

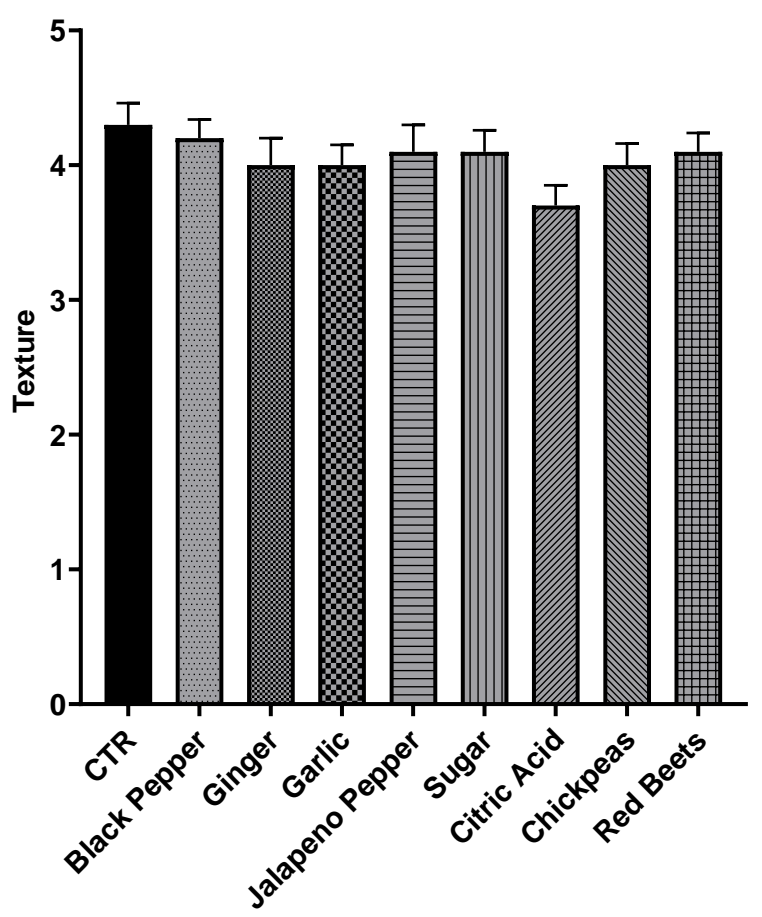

Fig.3: Comparing texture evaluation of all 8 flavors to the control.

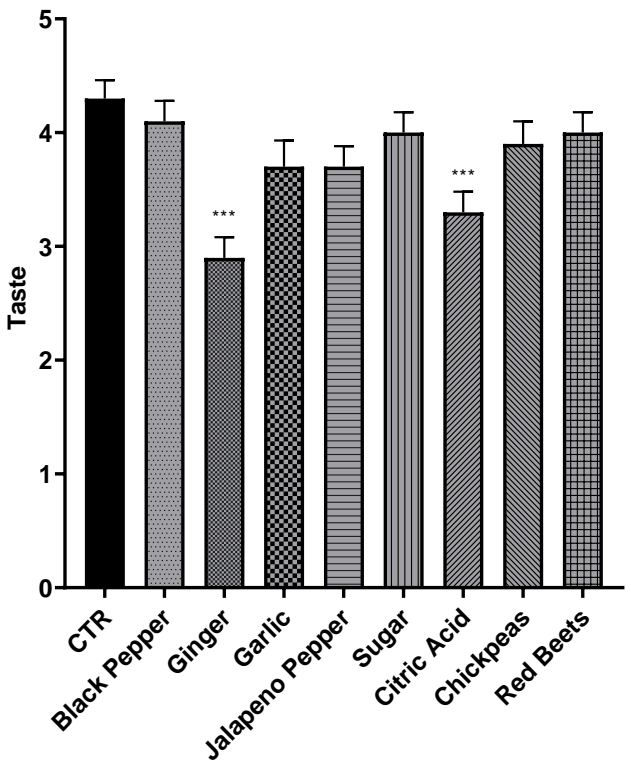

Fig.4: Comparing taste evaluation of all 8 flavors to the control.

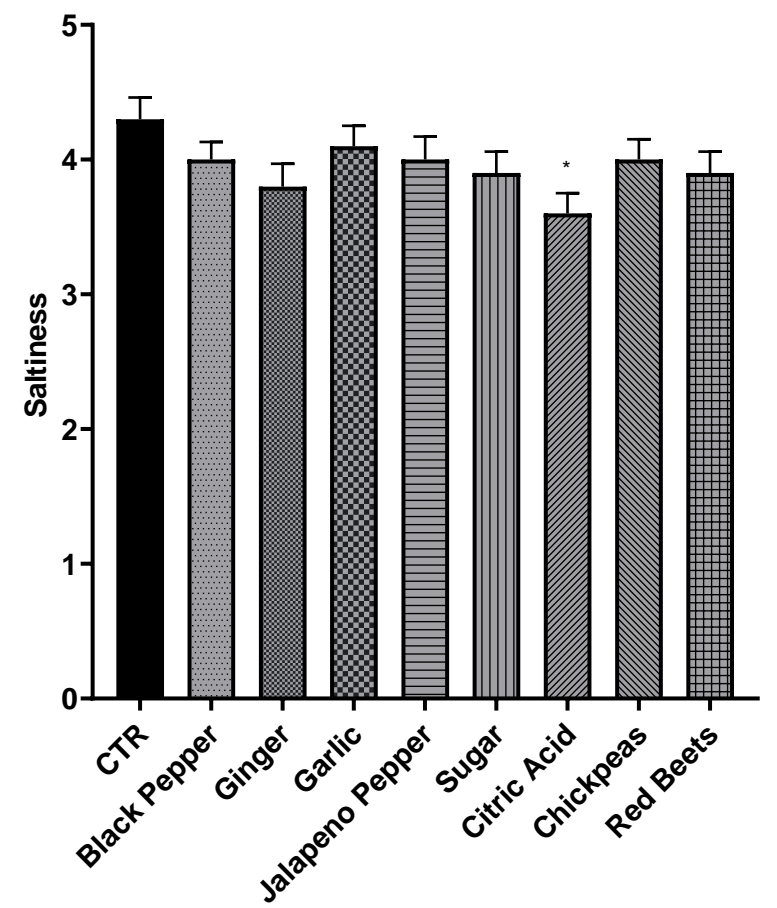

Fig.5: Comparing saltiness evaluation of all 8 flavors to the control.

\subsection{Sourness}

For the test of sourness, the panelists evaluated all samples and reported their findings on a Likert scale ranging from 1 to 5 (where "1" was "least liked" and "5" was "most liked"). The panelists did not report any difference in the sourness of any of the eight samples compared to the control (4.20 \pm 0.16 ; Fig. 6).

\subsection{Overall acceptability}

For the test of overall acceptability, the panelists evaluated all samples and reported their findings on a Likert scale ranging from 1 to 5 (where " 1 " was "least liked" and " 5 " was "most liked"). The panelists did not favor any of the samples above the control in terms of overall acceptability; however, they expressed a significant decrease in overall acceptability of the "Ginger" $(3.30 \pm 0.16 ; \mathrm{p}<0.001)$, "Garlic" $\quad(3.60 \pm 0.23 ; \quad \mathrm{p}<0.01)$, "Jalapeno Pepper" (3.70 $\pm 0.19 ; \mathrm{p}<0.01)$, and "Citric Acid" (3.40 \pm 0.21 ; $\mathrm{p}<0.001)$ vs. control (4.50 \pm 0.14 ; Fig. 7).

\subsection{Correlation test}

In a Pearson's Correlation test between the different sensory characteristics and overall acceptability, we determined that taste, odor, and texture had the highest correlation with the overall acceptability of the product (94\%, $91.5 \%$, and $82.3 \%$, respectively; Table 2). Saltiness had a slightly lower correlation with the overall acceptability of the product $(70.9 \%)$; however, color and 
sourness did not exhibit a significant correlation with the product's overall acceptability.

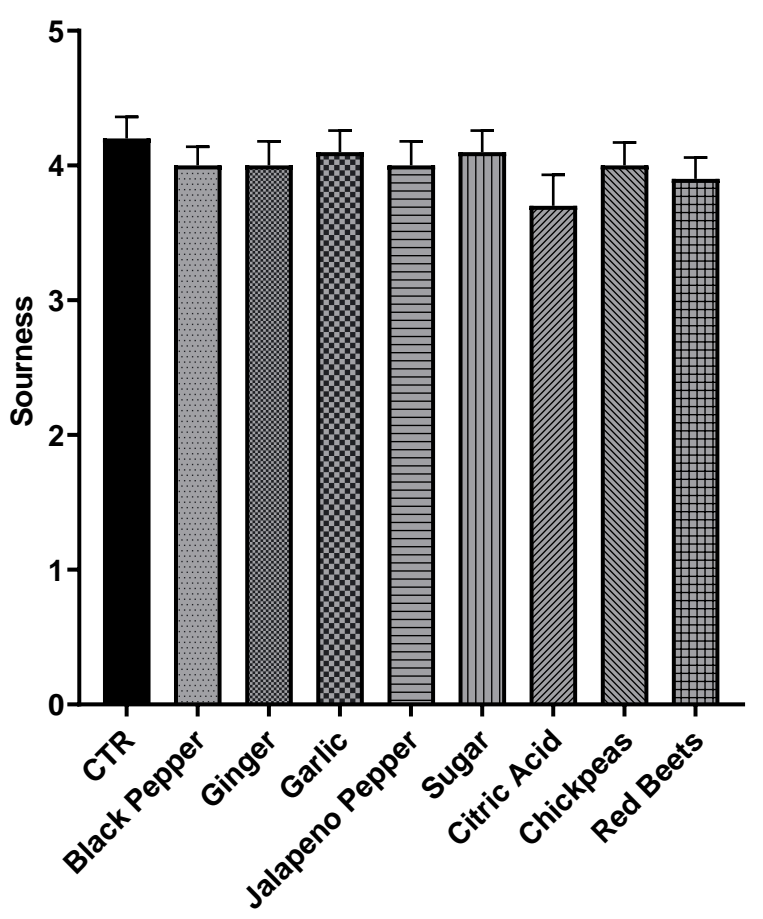

Fig.6: Comparing sourness evaluation of all 8 flavors to the control.

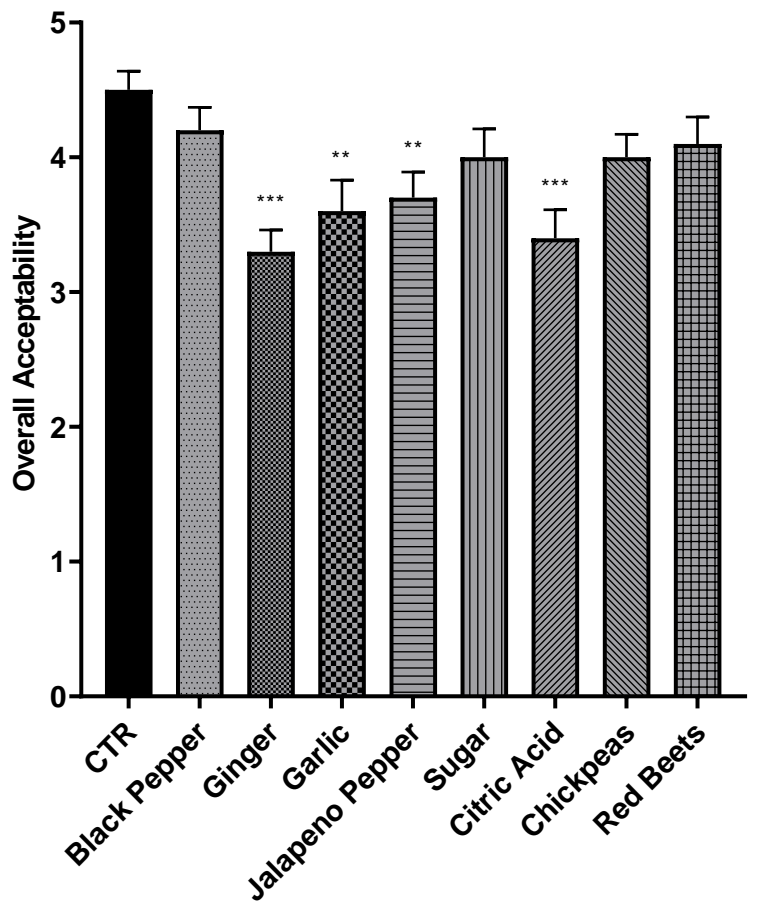

Fig.7: Comparing overall acceptability of all 8 flavors to the control.
Table 2: Pearson's Correlation test between the different sensory characteristics of snake melon pickles

\begin{tabular}{l|cccccl} 
& Color & Texture & Taste & Saltiness & Sourness & $\begin{array}{l}\text { Overall } \\
\text { Acceptability }\end{array}$ \\
\hline Odor & $\mathbf{0 . 4 7 8}$ & $.876^{* *}$ & $.900^{* *}$ & $.743^{*}$ & $.674^{*}$ & $.915^{* *}$ \\
Color & & $.697^{*}$ & $\mathbf{0 . 2 5 9}$ & $.735^{*}$ & $.831^{* *}$ & 0.317 \\
Texture & & & $.729^{*}$ & $.880^{* *}$ & $.805^{* *}$ & $.823^{* *}$ \\
Taste & & & & $.706^{*}$ & $\mathbf{0 . 5 0 8}^{*}$ & $.940^{* *}$ \\
Saltiness & & & & & $.878^{* *}$ & $.709^{*}$ \\
Sourness & & & & & & 0.505 \\
\hline
\end{tabular}

**: correlation is highly significant (at 0.01 level)

*: correlation is significant (at 0.05 level)

\section{CONCLUSION}

Our results indicate a clear and strong positive correlation between taste, odor, and texture with the overall acceptability of snake melon pickle products. The more noticeable off-putting flavors that were used where ginger and citric acid salt, it seemed that both additives did not agree well with the Lebanese palate. Even though it is a common practice to use garlic and green peppers as additives with pickling products, and although the panelists did not report any impact of both additives on the odor, taste, and texture; it was surprising to detect a reduction in the overall acceptability of both garlic and Jalapeno pepper containing samples. It was clear that new snake melon pickle recipes can be made and introduced to the public in an effort to increase consumption of a functional food fermented product and reduce the loss of fresh crops by means of creating new product that has an extended shelflife.

\section{ACKNOWLEDGEMENTS}

The authors thank all who volunteered for this study.

\section{REFERENCES}

[1] Jahanbakhshi, A. (2018). Determination of some engineering properties of snake melon (Cucumis melo var. flexuosus) fruit. Agricultural Engineering International: CIGR Journal, 20(1), 171-176

[2] Merheb, J., Pawełkowicz, M., Branca, F., BolibokBrągoszewska, H., Skarzyńska, A., Pląder, W., \& Chalak, L. (2020). Characterization of Lebanese Germoplasm of Snake Melon (Cucumis melo subsp. melo var. flexuosus) Using Morphological Traits and SSR Markers. Agronomy, 10(9), 1293. https://doi.org/10.3390/agronomy 10091293

[3] Abed, M. Y. (2018). Genetic Improvement of Yield and Fruit Traits in Snake Cucumber (Cucumis melo var. flexuosus L.) by Individual Selection. Asian Journal of Biotechnology and Genetic Engineering, 1(2), 1-10. Retrieved from https://www.journalajbge.com/index.php/AJBGE/article/vie w/426 
[4] Paris, H. (2011). Semitic-language records of snake melons (Cucumis melo, Cucurbitaceae) in the medieval period and the "piqqus" of the "faqqous". Genetic Resources and Crop Evolution, 59(1), 31-38. https://doi.org/10.1007/s10722-0119664-y

[5] Mariod, A., Mirghani, M., \& Hussein, I. (2017).Unconventional Oilseeds and Oil Sources: Cucumis melo var. flexuosus The Armenian Cucumber or Snake Melon, (pp.85-88), 10.1016/B978-0-12-809435-8.00015-9

[6] Milner, J. A. (2000). Functional foods: the US perspective. The American Journal of Clinical Nutrition, 71(6), 1654S-1659S. https://doi.org/10.1093/ajcn/71.6.1654s

[7] Jovanovic-Malinovska, R., Kuzmanova, S., \& Winkelhausen, E. (2014). Oligosaccharide Profile in Fruits and Vegetables as Sources of Prebiotics and Functional Foods. International Journal of Food Properties, 17(5), 949965. https://doi.org/10.1080/10942912.2012.680221

[8] Shi, J., Mazza, G., \& Maguer, L. M. (2002). Functional Foods: Biochemical and Processing Aspects, Volume 2 (Functional Foods and Nutraceuticals) (1st ed.). CRC Press.

[9] Mazza, G. (1998). Functional Foods: Biochemical and Processing Aspects, Volume 1 (Functional Foods and Nutraceuticals) (1st ed.). CRC Press.

[10] Ninfali, P., \& Angelino, D. (2013). Nutritional and functional potential of Beta vulgaris cicla and rubra. Fitoterapia, 89, 188-199. https://doi.org/10.1016/j.fitote.2013.06.004

[11] Moreno-Escamilla, J. O., de la Rosa, L. A., López-Díaz, J. A., Rodrigo-García, J., Núñez-Gastélum, J. A., \& AlvarezParrilla, E. (2015). Effect of the smoking process and firewood type in the phytochemical content and antioxidant capacity of red Jalapeño pepper during its transformation to chipotle pepper. Food Research International, 76, 654-660. https://doi.org/10.1016/j.foodres.2015.07.031

[12] Chonpathompikunlert, P., Wattanathorn, J., \& Muchimapura, S. (2010). Piperine, the main alkaloid of Thai black pepper, protects against neurodegeneration and cognitive impairment in animal model of cognitive deficit like condition of Alzheimer's disease. Food and Chemical Toxicology, 48(3), 798-802. doi:10.1016/j.fct.2009.12.009

[13] Butt, M. S., Pasha, I., Sultan, M. T., Randhawa, M. A., Saeed, F., \& Ahmed, W. (2013). Black Pepper and Health Claims: A Comprehensive Treatise. Critical Reviews in Food Science and Nutrition, 53(9), 875-886. https://doi.org/10.1080/10408398.2011.571799

[14] Trinidad, T.P., Sagum, R.S., de Leon, M.P., Mallillin, A.C., \& Borlagdan, M.P. (2012). Zingiber Officinale and Curcuma Longa as Potential Functional Foods/Ingredients. Food and Public Health, 2(2), 1-4. https://doi.org/10.5923/j.fph.20120202.01

[15] Mao, Q. Q., Xu, X. Y., Cao, S. Y., Gan, R. Y., Corke, H., Beta, T., \& Li, H. B. (2019). Bioactive Compounds and Bioactivities of Ginger (Zingiber officinale Roscoe). Foods, 8(6), 185. https://doi.org/10.3390/foods8060185

[16] Chang, R.B., Water, H., \& Liman, E.R. (2010). A proton current drives action potentials in genetically identified sour taste cells. PNAS, 107(51): 22320-22325. https://doi.org/10.1073/pnas.1013664107 